\title{
Hydrogen-Bonding Directed Reversal of Enantioselectivity
}

\author{
Wei Zeng, ${ }^{\dagger}$ Guo-Ying Chen, ${ }^{\dagger}$ Yong-Gui Zhou, ${ }^{*},+, \ddagger$ and Yu-Xue Li ${ }^{*}, \neq$ \\ Dalian Institute of Chemical Physics, CAS, 457 Zhongshan Lu, Dalian 116023, China, and State Key Laboratory of \\ Organometallic Chemistry, Shanghai Institute of Organic Chemistry, CAS, 354 Fenglin Lu, Shanghai 200032, China
}

Received October 12, 2006; E-mail: ygzhou@dicp.ac.cn; liyuxue@mail.sioc.ac.cn

The preparation of both enantiomers of a chiral compound is still a vital task in pharmaceutical and bioorganic chemistry. ${ }^{1}$ Basically, it can be achieved with the use of both enantiomers of a chiral ligand, respectively, in a catalytic asymmetric process. However, the two enantiomers of a chiral ligand are not always easily available from natural chiral sources, such as amino acids, carbohydrates, and alkaloids. Alternatively, the enantioselectivity can be reversed by using different metals ${ }^{2}$ in the presence of the same ligands, including additives, ${ }^{3}$ or changing the reaction parameters (temperature ${ }^{4}$ and solvents ${ }^{5}$ ) or other methods. ${ }^{6}$ Although the use of hydrogen bonding to accelerate or catalyze certain reactions has been well documented recently, ${ }^{7}$ reversal of enantioselectivity directed by hydrogen bonding is still rare. ${ }^{8}$ We envisage that the formation of hydrogen bonds may reverse the enantioselectivity if ligands were properly designed. The reversal could be caused by the variation of reaction transition states (Figure 1), in which transition state A is common. Both substrates SM1 and SM2 coordinate with the central metal M, but in transition state B, SM2 can coordinate with the central metal $\mathrm{M}$, while the other substrate SM1 has an interaction with $\mathrm{NH}_{2}$ of the ligand through hydrogen bonding. Thus, different enantiofacial attack was afforded, leading to the reversal of enantioselectivity. In this Communication, we present a hydrogen-bond-directed reversal of enantioselectivity in AgOAc-catalyzed [3+2] cycloaddition of azomethine ylides.

In our initial study, we chose the cycloaddition of iminoester $\mathbf{2 a}$ with dimethyl maleate as the model reaction, which is a useful way to form highly substituted pyrrolidine rings ${ }^{9}$ (Table 1). Ligands 1a-e could be conveniently synthesized according to the known literature method. ${ }^{10}$ The reaction proceeded smoothly in the presence of $\mathrm{AgOAc} / \mathbf{1 a}$ in $\mathrm{Et}_{2} \mathrm{O}$, and only endo cycloaddition product was detected with $76 \%$ ee. To our delight, the opposite absolute configuration of adduct $\mathbf{3 a}$ was obtained with $83 \%$ ee when ligand 1b was used, whose substituents on the $\mathrm{N}$ atom are $\mathrm{H}$ atoms. To achieve better enantioselectivity, we replaced phenyl groups in 1a/ $\mathbf{1 b}$ with 3,5-dimethylphenyl (1c/1d). Both enantiomers of adduct 3a were obtained with $84 \%$ and $-84 \%$ ees, respectively (entries 3 and 4). The ee was improved to $92 \%$ using 1c when the reaction was run at $-25^{\circ} \mathrm{C}$. Adduct $3 \mathbf{a}$ with $92 \%$ ee and opposite absolute configuration was obtained using ligand $1 \mathbf{d}$ at $-25^{\circ} \mathrm{C}$. Thus, both enantiomers of adduct $\mathbf{3} \mathbf{a}$ can be obtained with excellent enantioselectivity using $\mathrm{AgOAc} / \mathbf{1 c} /-25{ }^{\circ} \mathrm{C}$ and $\mathrm{AgOAc} / \mathbf{1 d} /-25{ }^{\circ} \mathrm{C}$, respectively.

To explore the scope of the hydrogen bond-directed reversal of enantioselectivity in cycloaddition of azomethine ylides, a variety of iminoester substrates derived from aldehydes with different steric and electronic properties were examined (Table 2). All reactions went to completion within $4 \mathrm{~h}$ in high isolated yields (91-98\%). Reversal of the absolute configuration was realized in the reactions of various iminoesters $2 \mathbf{a}-\mathbf{f}$ and dimethyl maleate regardless of

$\dagger$ Dalian Institute of Chemical Physics.

¥ Shanghai Institute of Organic Chemistry.

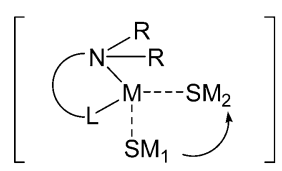

Transition State A

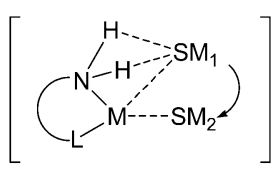

Transition State B

Figure 1. Proposed variation of transition states.

Table 1. AgOAc-Catalyzed Asymmetric Cycloaddition of $2 \mathbf{a}^{\mathbf{a}}$
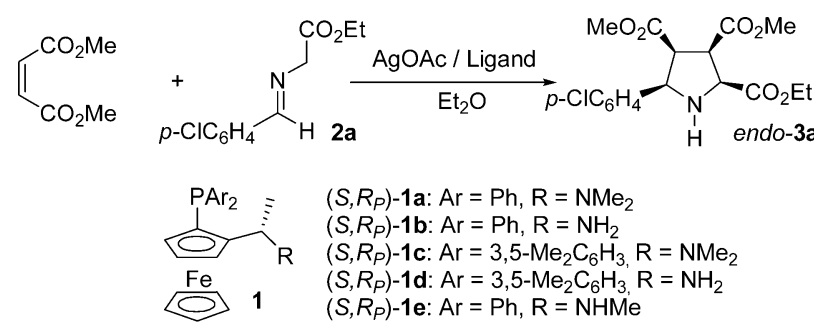

\begin{tabular}{ccrcr}
\hline entry & ligand & $T\left({ }^{\circ} \mathrm{C}\right)$ & yield $^{b}(\%)$ & $\operatorname{ee}^{c}(\%)$ \\
\hline 1 & 1a & 0 & 95 & -76 \\
2 & 1b & 0 & 91 & 83 \\
3 & 1c & 0 & 95 & -84 \\
4 & 1d & 0 & 94 & 84 \\
5 & 1e & 0 & 71 & -19 \\
6 & 1c & -25 & 95 & -92 \\
7 & 1d & -25 & 90 & 92 \\
\hline
\end{tabular}

${ }^{a}$ Conditions: iminoester 2a (1.0 equiv), dimethyl maleate (1.5 equiv), $\mathrm{AgOAc}(3 \mathrm{~mol} \%)$, ligand $(3.3 \mathrm{~mol} \%)$, concentration $=0.12 \mathrm{M} .{ }^{b}$ Isolated yields based on 2a. ${ }^{c}$ Determined by HPLC.

the steric hindrance and electronic properties of the benzene ring of iminoester 2. Other dipolarophiles such as tert-butylacrylate and $\mathrm{N}$-phenylmaleimide were also tested; successful reversal of the absolute configuration was observed (entries 11-16).

To further understand the role of hydrogen bonding, a computational study was performed. As shown in Figure 2, the complexes formed by $\mathbf{2 b}$ and $\mathrm{Ag}-\mathbf{1 a} / \mathbf{1 b}$ have four possible types of structures (C1 to C4). Eight structures for $1 \mathbf{a}(\mathrm{R}=\mathrm{Me})$ and $\mathbf{1 b}(\mathrm{R}=\mathrm{H})$ of $\mathrm{C} 1$ to $\mathbf{C} 4$ type are fully optimized by $\mathrm{B} 3 \mathrm{LYP}^{11}$ method with the Gaussian 03 program. ${ }^{12}$ For $\mathrm{C}, \mathrm{H}$ and $\mathrm{N}$, the $6-31 \mathrm{G}^{*}$ basis set was used; for Ag, the Lanl2DZ basis set with effective core potential $(\mathrm{ECP})^{13}$ was used. The results show that the most stable complexes for both $\mathbf{1 a}$ and $\mathbf{1 b}$ are $\mathbf{C 2}$ type (Figure 3).

Figure 3 shows that there is large space at both sides of the iminoester in C2-1b. The two carbonyl groups of the dimethyl maleate can coordinate with the Ag center. Furthermore, they may form two hydrogen bonds with the $\mathrm{NH}_{2}$ group. This interaction can stabilize the negatively charged oxygen atom in the possible zwitterionic intermediate and the transition state..$^{\text {h }}$ This indicates that it is favorable for C2-1b to be attacked from the top face. While in C2-1a, the dimethylamino group cannot form hydrogen bonds, and the methyl groups will cause steric repulsion. Therefore the dimethyl maleate will attack from the bottom face of C2-1a, 
Table 2. AgOAc-Catalyzed Asymmetric Cycloadditiona

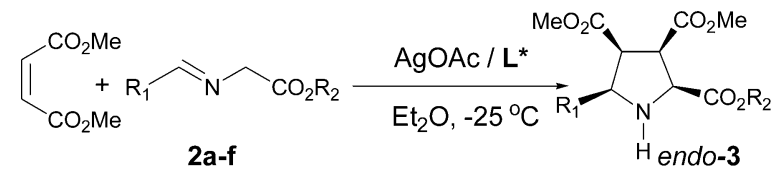

\begin{tabular}{|c|c|c|c|c|}
\hline entry & $\mathrm{R}_{1} / \mathrm{R}_{2}$ in 2 & ligand & yield $/ 3$ & ee $(\%)^{c}$ \\
\hline 1 & $\mathrm{Ph} / \mathrm{Me}(\mathbf{2 b})$ & 1d & $95(\mathbf{3 b})$ & 90 \\
\hline 2 & $\mathrm{Ph} / \mathrm{Me}(\mathbf{2 b})$ & 1c & $96(\mathbf{3 b})$ & -85 \\
\hline 3 & $p$-anisyl/Me (2c) & 1d & $93(\mathbf{3 c})$ & 90 \\
\hline 4 & $p$-anisyl/Me (2c) & 1c & $98(\mathbf{3 c})$ & -87 \\
\hline 5 & 4-chlorophenyl/Me (2d) & 1d & $96(3 \mathbf{d})$ & 88 \\
\hline 6 & 4-chlorophenyl/Me (2d) & $1 c$ & $91(\mathbf{3 d})$ & -91 \\
\hline 7 & $o$-toluyl/Me (2e) & 1d & $95(3 \mathbf{e})$ & 88 \\
\hline 8 & $o$-toluyl/Me (2e) & 1c & $95(3 \mathbf{e})$ & -85 \\
\hline 9 & 2-naphthyl/Me (2f) & 1d & 98 (3f) & 91 \\
\hline 10 & 2-naphthyl/Me (2f) & 1c & $91(\mathbf{3 f})$ & -87 \\
\hline $11^{d}$ & $\mathrm{Ph} / \mathrm{Me}(\mathbf{2 b})$ & 1d & $90(\mathbf{3 g})$ & 97 \\
\hline $12^{d}$ & $\mathrm{Ph} / \mathrm{Me}(2 \mathbf{b})$ & 1c & $90(\mathbf{3 g})$ & -78 \\
\hline $13^{d}$ & $o$-toluyl/Me (2e) & 1d & $96(\mathbf{3 h})$ & 94 \\
\hline $14^{d}$ & $o$-toluyl/Me (2e) & 1c & $89(\mathbf{3 h})$ & -79 \\
\hline $15^{e}$ & $\mathrm{Ph} / \mathrm{Me}(\mathbf{2 b})$ & 1d & $98(\mathbf{3 i})$ & 36 \\
\hline $16^{e}$ & $\mathrm{Ph} / \mathrm{Me}(\mathbf{2 b})$ & $1 c$ & $98(\mathbf{3 i})$ & -92 \\
\hline
\end{tabular}

${ }^{a}$ Conditions: iminoesters 2 (1.0 equiv), dimethyl maleate (1.5 equiv), $\operatorname{AgOAc}(3 \mathrm{~mol} \%)$, ligand $(3.3 \mathrm{~mol} \%)$, concentration $=0.12 \mathrm{M}$, at $-25^{\circ} \mathrm{C}$ ${ }^{b}$ Isolated yields. ${ }^{c}$ Determined by HPLC. ${ }^{d} t$-Butylacrylate was used. ${ }^{e} N$ phenylmaleimide was used.

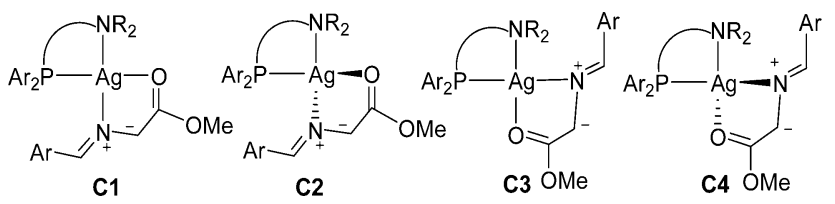

Figure 2. The four types of complexes formed by $\mathbf{2 b}$ and Ag-1a/1 $\mathbf{b}$.

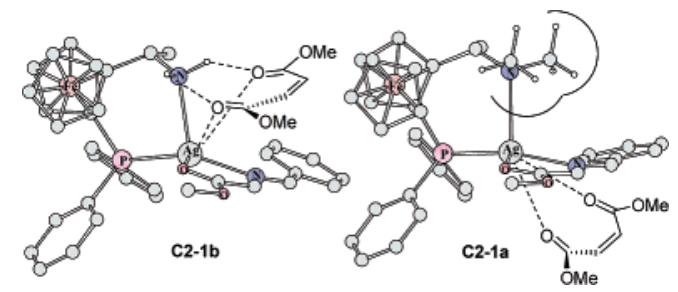

Figure 3. The optimized structures of $\mathbf{C 2 - 1 \mathbf { b }}$ and $\mathbf{C 2 - 1 a}$. The hydrogen atoms that are not involved in the reactions are omitted for clarity. Calculated at B3LYP/6-31*/Lanl2DZ level.

hence, the enantioselectivity is reversed. According to the above model, addition of competitive hydrogen-bond donors should destroy the hydrogen binding, decrease of enantioselectivity should be observed, and so, cycloaddition of $\mathbf{2 a}$ and dimethyl maleate was performed using $\mathrm{AgOAc}-\mathbf{1 b}$ as catalyst in the presence of additives ( $t$-amyl alcohol, EtOH) at $0{ }^{\circ} \mathrm{C}$, enantioselectivity was decreased to $79 \%$ and $78 \%$ from $83 \% .14$

${ }^{1} \mathrm{H}$ NMR titration experiments and Job's method were employed to probe the hydrogen binding between the complex AgOAc-1b and dimethyl maleate. A significant change of the $\mathrm{N}-\mathrm{H}$ chemical shift was observed, and an approximate 1:1 complex was indicated. ${ }^{14}$

In summary, a successful stereochemical reversal was achieved in AgOAc catalyzed [3+2] cycloaddition of azomethine ylides by the formation of hydrogen bonding between ligand and reactant. Density-functional theory studies proposed a reasonable mechanism of the reversal of the enantioselectivity. The strategy may provide some useful hints for ligand design.

Acknowledgment. We are grateful for the financial support from National Science Foundation of China (Grant 20532050).
Supporting Information Available: Spectroscopic data, experimental details, computational methods, and complete ref 12 . This material is available free of charge via the Internet at http://pubs.acs.org.

\section{References}

(1) For reviews, see: (a) Zanoni, G.; Castronovo, F.; Franzini, M.; Vidari, G.; Giannini, E. Chem. Soc. Rev. 2003, 32, 115. (b) Sibi, M. P.; Liu, M. Curr. Org. Chem. 2001, 5, 719.

(2) For selected examples, see: (a) Du, D. M.; Lu, S. F.; Fang, T.; Xu, J. J. Org. Chem. 2005, 70, 3712. (b) Bertozzi, F.; Pineschi, M.; Macchia, F. Arnold, L. A.; Minnaard, A. J.; Feringa, B. L. Org. Lett. 2002, 4, 2703. (c) Murakami, M.; Itami, K.; Ito, Y. J. Am. Chem. Soc. 1999, 121, 4130 (d) Yabu, K.; Masumoto, S.; Yamasaki, S.; Hamashima, Y.; Kanai, M.; Du, W.; Curran, D. P.; Shibasaki, M. J. Am. Chem. Soc. 2001, 123, 9908 (e) Nishibayashi, Y.; Segawa, K.; Ohe, K.; Uemura, S. Organometallics $1995,14,5486$.

(3) For selected examples, see: (a) Mao, J.; Wan, B.; Zhang, Z.; Wang, R.; Wu, F.; Lu, S. J. Mol. Catal. A 2005, 225, 33. (b) Lutz, F.; Igarashi, T. Kawasaki, T.; Soai, K. J. Am. Chem. Soc. 2005, 127, 12206. (c) Kawamura, M.; Kobayashi, S. Tetrahedron Lett. 1999, 40, 3213. (d) Gothelf, K. V.; Hazell, R. G.; Jørgensen, K. A. J. Org. Chem. 1998, 63, 5483. (e) Kobayashi, S.; Ishitani, H. J. Am. Chem. Soc. 1994, 116, 4083. (f) Kobayashi, S.; Ishitani, H.; Hachiya, I.; Araki, M. Tetrahedron 1994, 50,11623 .

(4) For selected examples, see: (a) Berkessel, A.; Mukherjee, S.; Lex, J. Synlett 2006, 41. (b) Trost, B. M.; Fettes, A.; Shireman, B. T. J. Am Chem. Soc. 2004, 126, 2660. (c) Casey, C. P.; Martins, S. C.; Fagan, M. A. J. Am. Chem. Soc. 2004, 126, 5585. (d) Sibi, M. P.; Gorikunti, U.; Liu, M. Tetrahedron 2002, 58, 8357.

(5) For selected examples, see: (a) Arseniyadis, S.; Valleix, A.; Wagner, A Mioskowski, C. Angew. Chem., Int. Ed. 2004, 43, 3314. (b) Zhou, J.; Ye, M. C.; Huang, Z. Z.; Tang, Y. J. Org. Chem. 2004, 69, 1309. (c) Kanai, M.; Koga, K.; Tomioka, K. J. Chem. Soc., Chem. Commun. 1993, 1248 (d) Johannsen, M.; Jørgensen, K. A. Tetrahedron 1996, 52, 7321

(6) Selected examples of reversal due to steric effect, pressure, substituents on coordination atoms, and metal/ligand ratio, see: (a) Kitagawa, $\mathrm{O}$; Matsuo, S.; Yotsumoto, K.; Taguchi, T. J. Org. Chem. 2006, 71, 2524 (b) Kuwano, R.; Sawamura, M.; Ito, Y. Bull. Chem. Soc. Jpn. 2000, 73, 2571. (c) Danjo, H.; Higuchi, M.; Yada, M.; Imamoto, T. Tetrahedron Lett. 2004, 45, 603. (d) Clyne, D. S.; Mermet-Bouvier, Y. C.; Nomura, N.; RajanBabu, T. V. J. Org. Chem. 1999, 64, 7601. (e) Nomura, N.; Mermet-Bouvier, Y. C.; RajanBabu, T. V. Synlett 1996, 745. (f) Evans, D. A.; Kozlowski, M. C.; Murray, J. A.; Burgey, C. S.; Campos, K. R.; Connell, B. T.; Staples, R. J. J. Am. Chem. Soc. 1999, 121, 669 and references cited therein

(7) (a) Pihko, P. M. Angew. Chem., Int. Ed. 2004, 43, 2062. (b) Dalko, P. I.; Moisan, L. Angew. Chem., Int. Ed. 2004, 43, 5138. (c) Noyori, R. Hashiguchi, S. Acc. Chem. Res. 1997, 30, 97. (d) Taylor, M. S.; Jacobsen, E. N. Angew. Chem., Int. Ed. 2006, 45, 1520 and references cited therein. (e) Noyori, R.; Ohkuma, T. Angew. Chem., Int. Ed. 2001, 40, 40. (f) Huang, Y.; Unni, A. K.; Thadani, A. N.; Rawal, V. H. Nature 2003, 424, 146. (g) Du, H.; Zhao, D.; Ding, K. Chem.-Eur. J. 2004, 10, 5964. (h) Deng, X. M.; Cai, P.; Ye, S.; Sun, X. L.; Liao, W. W.; Li, K.; Tang, Y.; Wu, Y. D.; Dai, L. X. J. Am. Chem. Soc. 2006, 128, 9730. (i) Breit, B. Seiche, W. J. Am. Chem. Soc. 2003, 125, 6608. (j) Weis, M.; Waloch, C.; Seiche, W.; Breit, B. J. Am. Chem. Soc. 2006, 128, 4188.

(8) For examples of reversal of enantioselectivity due to $\mathrm{OH}$ or $\mathrm{NH}_{2}$, see (a) Hoarau, O.; Aït-Haddou, H.; Daran, J. C.; Cramailère, D.; Balavoine, G. G. A. Organometallics 1998, 18, 4718. (b) Beliczey, J.; Giffels, G.; Kragl, U.; Wandrey, C. Tetrahedron: Asymmetry 1997, 8, 1529.

(9) For successful examples using $\mathrm{Ag}, \mathrm{Cu}, \mathrm{Zn}$ catalysts, see: (a) Bonini, B F.; Boschi, F.; Comes-Franchini, M.; Fochi, M.; Fini, F.; Mazzanti, A. Ricci, A. Synlett 2006, 543. (b) Zeng, W.; Zhou, Y.-G. Org. Lett. 2005 7, 5055. (c) Stohler, R.; Wahl, F.; Pfaltz, A. Synthesis 2005, 1431. (d) Alemparte, C.; Blay, G.; Jørgensen, K. A.; Org. Lett. 2005, 7, 4569. (e) Chen, C.; Li, X.; Schreiber, S. L. J. Am. Chem. Soc. 2003, 125, 10174 (f) Longmire, J. M.; Wang, B.; Zhang, X. J. Am. Chem. Soc. 2002, 124 13400. (g) Liamas, T.; Arrayás, R. G.; Carretero, J. C. Org. Lett. 2006, 8 , 1795. (h) Yan, X.-X.; Peng, Q.; Zhang, Y.; Zhang, K.; Hong, W.; Hou, X.-L.; Wu, Y.-D. Angew. Chem., Int. Ed. 2006, 45, 1979. (i) Catrera, S.; Arrayás, R. G.; Carretero, J. C. J. Am. Chem. Soc. 2005, 127, 16394. (j) Gao, W.; Zhang, X.; Raghunath, M. Org. Lett. 2005, 7, 4241. (k) Oderaotoshi, Y.; Cheng, W.; Fujitomi, S.; Kasano, Y.; Minakata, S.; Komatsu, M. Org. Lett. 2003, 5, 5043. (1) Gothelf, A. S.; Gothelf, K. V. Hazell, R. G.; Jørgensen, K. A. Angew. Chem., Int. Ed. 2002, 41, 4236.

(10) Hayashi, T.; Mise, T.; Fukushima, M.; Kagotani, M.; Nagashima, N.; Hamada, Y.; Matsumoto, A.; Kawakami, S.; Konishi, M.; Yamamoto, K.; Kumada, M. Bull. Chem. Soc. Jpn. 1980, 53, 1138.

(11) (a) Becke, A. D. Phys. Rev. A: At., Mol., Opt. Phys. 1988, 38, 3098. (b) Becke, A. D. J. Chem. Phys. 1993, 98, 1372, 5648. (c) Lee, C.; Yang, W.; Parr, R. G. Phys. Rev. B: Condens. Matter Mater. Phys. 1988, 37 , 785 .

(12) The calculations were performed with Gaussian 03 program: Frisch, M. J.; et al. Gaussian 03, revision C.02; Gaussian, Inc.: Wallingford, CT, 2004.

(13) Wadt, W. R.; Hay, P. J. J. Chem. Phys. 1985, 82, 284

(14) See Supporting Information for details. JA067346F 